\title{
«EL CASO BILDU»: CONTINUIDAD Y RUPTURA EN LA DOCTRINA DEL TRIBUNAL CONSTITUCIONAL SOBRE LA ILEGALIZACIÓN DE FORMACIONES POLÍTICAS
}

\author{
MERCEDES IGLESIAS BÁREZ \\ Profesora Contratada Doctora de Derecho Constitucional \\ Universidad de Salamanca
}

\begin{abstract}
SUMARIO.
I. Introducción

II. Las características procesales de la prohibición de presentación de candidaturas en el Caso Bildu

III. La doctrina constitucional en materia de sucesión fraudulenta de partidos políticos ilegalizados y disueltos (art. 44.4 LOREG). Su aplicación al Caso Bildu
\end{abstract}

\section{INTRODUCCIÓN}

Han transcurridos ocho años ya desde que la Sala Especial del Tribunal Supremo declarara, mediante Sentencia de 27 de marzo de $2003^{1}$, la ilegalización y disolución de los partidos políticos Euskal Herritarrok, Herri Batasuna y Batasuna, al acreditarse fehacientemente que estas formaciones políticas habían incurrido en la causa establecida en el art. 10. 2 c) de la Ley 6/2002, de 27 de junio, de Partidos Políticos, que habilita a la Sala Especial a decretar la disolución de un partido «cuando de forma reiterada y grave su actividad vulnere los principios democráticos o persiga deteriorar o destruir el régimen de libertades o imposibilitar o eliminar el sistema democrático, mediante las conductas a que se refiere el art. 9 de la Ley». A pesar de la Sentencia de disolución, Batasuna ha intentado re-

1 El Tribunal Constitucional, como es bien sabido, desestimó los recursos de amparo interpuestos en su momento en virtud de las SSTC 5/2004 y 6/2004, ambas de 16 de enero. 
constituirse políticamente en fraude de ley sirviéndose de otras entidades políticas (agrupaciones de electores, partidos ya existentes o creados ex novo), que le permitieran seguir participando en los procesos electorales y llegar así a las instituciones políticas. Hasta las elecciones al Parlamento Europeo, celebradas el 7 de junio de 2009, en la inmensa mayoría de los casos el Tribunal Constitucional (en adelante TC) confirmó las decisiones de la Sala Especial que decretaban la anulación de presentación de candidaturas a los diferentes procesos electorales o bien que declararon la ilegalización de los partidos políticos Acción $\mathrm{Na}$ cionalista Vasca (ANV) y el Partido Comunista de las Tierras Vascas (PCTV) ${ }^{2}$.

La STC 129/2009 en el Caso de la Coalición Iniciativa Internacionalista-Izquierda de los Pueblos manifestó por vez primera el entrentamiento entre el Tribunal Supremo y el TC TC $^{3}$ La decisión de la Sala Especial de 16 de mayo de 2009, que prohibía a la Coalición presentar sus candidaturas, fue anulada por el TC por no demostrar de forma suficiente y razonable la sucesión fraudulenta entre Batasuna y la Coalición.

De nuevo la STC 62/2011, de 5 de mayo, en el llamado Caso Bildu, vuelve a quebrar esa trayectoria de sintonía entre los dos altos tribunales. A simple vista ambos supuestos guardan ciertos paralelismos. Bildu también es una coalición de partidos políticos y la STS de 1 de mayo de 2011 ha sido revocada por el TC, por lo que la Coalición ha podido presentarse a las elecciones. No obstante, las coincidencias acaban aquí. Un análisis más profundo de los supuestos, nos muestra que las verdaderas divergencias apuntan a aspectos tales como los componentes de la coalición, el tipo de elecciones celebradas o incluso el resultado electoral. Junto a estos elementos, la presión mediática y el debate político han coadyuvado a dotar a este caso de una especificidad propia, que no ha hecho más que acrecentar la complejidad de un caso ya de por sí difícil.

No cabe duda de que las especiales particularidades de los miembros de la Coalición ha sido un elemento determinante que ha decantado el sentido de la decisión del TC.

Bildu es una coalición de dos partidos, Eusko Alkartasuna (en adelante EA) y Alternatiba, de larga trayectoria política en el País Vasco, a los que se unen un número amplio de candidatos independientes. Además en Álava forma también parte de la Coalición el partido «Araba Bai», una escisión del partido «Aralar». EA, como es bien sabido, surgió de una escisión del Partido Nacionalista Vasco (PNV) en 1986, liderado en sus ini-

2 Caso Plataforma Nafarroako Autodeterminaziorako Bilguena (AuB), Sentencias de la Sala Especial de 3 de mayo de 2003 y STC 85/2003; Caso elecciones concejiles parciales, Sentencias de la Sala Especial de 5 de octubre 2003 y STC 176/2003; Caso agrupación electoral Herritarren Zerrenda (HZ), Sentencias de la Sala de 21 de mayo de 2004 y STC 99/2004; Caso agrupación de electores Aukera Guztiak, Sentencias de la Sala de 26 de marzo de 2005 y STC 68/2005. En las elecciones de abril de 2007 al Parlamento de Navarra y a las Juntas Generales en los Territorios Históricos y elecciones locales en Navarra, se utilizó coordinadamente un nuevo sistema consistente en la presentación de una agrupación de electores bajo el nombre de «Abertzale Sozialistak» y a la vez del partido político ANV, Sentencia de 5 de mayo de 2007 y Auto de 5 de mayo de 2007. Las SSTC 110 y 112/2007 desestimaron los recursos de amparo. También se impidió la creación del partido Abertzale Sozialisten Batasuna mediante el Auto de 22 de mayo de 2007. La Sala Especial declaró el 22 de mayo de 2008 la ilegalización de ANV y el PCTV, confirmada por la STC 31/2009. Por Auto y Sentencia de 8 de febrero de 2009 se anularon las candidaturas presentadas por el partido político Askatasuna y las agrupaciones electorales Arabako Demokrazia 3.000.000 y D3M y confirmadas por las SSTC 43 y 44/2009.

3 Sobre este caso vid. VÍRGALA FORURIA, E, «La admisión de iniciativa internacionalista a las elecciones europeas de 2009: el Tribunal Constitucional corrige acertadamente la decisión del Tribunal Supremo», Revista Española de Derecho Constitucional, n. 87, 2009. 
cios por el ex Lehendakari Carlos Garaikoetxea y cuyo período de mayor éxito electoral fueron los años finales de esa década; habiendo alcanzado cerca de doscientos mil votos tanto en las elecciones al Parlamento Vasco de 1986 como en las elecciones forales y municipales de 1987 (un porcentaje cercano al veinte por ciento de los votos). A partir de este momento comenzó su declive electoral y en las elecciones al Parlamento Vasco del año 2009 obtuvo tan sólo treinta y ocho mil votos (poco más de un tres por ciento). En Navarra, a partir de 2004 participó en coalición con el PNV, Aralar y Batzarre, en la Coalición Nafarroa Bai. No obstante, fue expulsada de la Coalición en febrero de 2011 debido a sus acuerdos estratégicos con Batasuna ${ }^{4}$. Estos contactos provocaron también una crisis interna dentro del partido, que dio lugar a la escisión del sector de EA más crítico con esta relación, que ha cristalizado en la constitución del partido Hamaikabat en mayo de 2009. Alternatiba, por su parte, tiene su origen en los resultados de las elecciones autonómicas del País Vasco de 2009 que convirtieron a Ezker Batua (Izquierda Unida en el País Vasco) en una fuerza extraparlamentaria, por lo que un sector que ya se había constituido como corriente interna se escindió y se constituyó en partido político en octubre de 2010 con aquel nombre; un partido, también, con escasa representación política.

Se trata, en consecuencia, de dos partidos legales y con una larga trayectoria de condena evidente y expresa de la violencia terrorista de ETA. Además junto a estos dos partidos forman parte de Bildu un gran número de candidatos independientes 5 .

Por otra parte, quizá convenga destacar la relevancia del tipo de elecciones celebradas. Mientras que en el Caso de Iniciativa Internacionalista-Izquierda de los Pueblos se trataba de unas elecciones que podemos calificar de "perfil bajo», las elecciones europeas, en este supuesto estaban en juego las elecciones municipales y a las Juntas Generales en el País Vasco, las elecciones municipales en Navarra y al Parlamento de Navarra, así como las elecciones locales en el Condado de Treviño (Burgos). Finalmente, Iniciativa Internacionalista-Izquierda de los Pueblos no obtuvo representación parlamentaria en las elecciones europeas, sin embargo, los resultados electorales de Bildu han sido espectaculares, lo que le ha permitido convertirse en la primera fuerza electoral en número de concejales en el País Vasco, obteniendo asimismo un elevado número de concejales en Navarra.

Tampoco es posible desechar en el análisis de las decisiones de la Sala Especial y del TC las presiones mediática y política a las que fueron sometidos los miembros de los altos tribunales ${ }^{6}$. No cabe entender en otro sentido el continuo seguimiento de los medios

4 Puede consultarse el comunicado de EA en su página web de 14 de febrero de 2011 donde rechaza la explusión de la coalición y la achaca a meros intereses partidistas del PNV y Aralar para hacerse con Nafarroa Bai.

5 Para la complejidad del proceso vid también NARVÁEZ RODRÍGUEZ, A, «Sentencia del Tribunal Supremo (Sala Especial del artículo 61 LOPJ) de 1 de mayo de 2011: Caso Bildu», La Ley, n. 7650, 2011, pág. 3. «La complejidad técnica de la pretensión de los recurrentes derivaba, no tanto de la dificultad intrínseca que supone en sí mismo el eventual descubrimiento de una trama defraudatoria, cuanto más de tener que aplicar el levantamiento del velo a una coalición electoral de la que formaban parte dos formaciones políticas democráticas y legales, supuestamente encargadas de dar cobertura a los candidatos vinculados a Batasuna que figuraran en las listas como independientes...».

6 Sobre estos factores distorsionadores vid entre otros el artículo de J. TAJADURA TEJADA, «La extralimitación del Tribunal Constitucional», El Correo, 10 de mayo de 2011, o el de J.L. MANZANARES «Una polémica Sentencia del Tribunal Constitucional», en el diario digital República.com. 
de comunicación del Caso Bildu, la «amenaza» del PNV de no apoyar al Gobierno de la Nación si no se permitía a la Coalición presentarse a las elecciones, o el «anuncio» por parte de destacados miembros del Grupo Parlamentario Socialista, en un intento de tranquilizar al PNV, de que se iba a producir una noticia «agradable», que no podía ser otra que la Sentencia del TC que revocó la decisión de la Sala Especial.

Todas estas circunstancias se reflejan también en la peculiaridad del propio proceso de decisión del TC, así como en la división que se produce en el seno de la Sala Especial y del TC a la hora de fallar su decisión. La Sentencia de la Sala Especial del 1 de mayo de 2011, que anuló la proclamación de las candidaturas de Bildu, contó con el voto mayoritario de nueve de sus dieciséis miembros. Hubo dos votos particulares; uno firmado por seis magistrados, que consideraban que los recursos del Abogado del Estado y del Ministerio Fiscal debían ser desestimados en su totalidad y un voto particular de estimación parcial de los recursos.

Por mayores vicisitudes atravesó la decisión del TC. El caso se resuelve en el Pleno tras repetidos empates en su Sala Segunda. La decisión se tomó por un estrecho margen: seis votos contra cinco y con cinco votos particulares.

Como puede apreciarse, la STC 62/ 2011 supone en buena medida un antes y un después en la historia de la aplicación de la Ley de Partidos e incluso como veremos un viraje en la doctrina que el propio TC ha construido sobre la sucesión fraudulenta de partidos políticos ilegalizados y disueltos.

\section{LAS CARACTERÍSTICAS PROCESALES DE LA PROHIBICIÓN DE PRESENTACIÓN DE CANDIDATURAS EN EL CASO BILDU. DE NUEVO SURGEN LAS DUDAS DE CONSTITUCIONALIDAD ACERCA DEL ART. 49 LOREG, EN RELACIÓN AL ART. 44.4 LOREG}

El Ministerio Fiscal y el Abogado del Estado interponen sendos recursos contencioso-electorales, al amparo de los arts. 49.1 y 5 y 44.4 de la LOREG, en la nueva redacción dada por la LO 3/2011, de 28 de enero. El marco de esta nueva normativa, que se aplica por primera vez en el caso Bildu, vuelve a ser la eficacia aplicativa de la Ley de Partidos y la prohibición del fraude de ley. A través de ella se pretende la persecución de la sucesión fraudulenta de Batasuna a lo largo de todo el proceso electoral, es decir, no sólo en el acto de proclamación de candidaturas (art. 49.5 LOREG), sino que se extiende también a la proclamación de electos (art. 108.4 bis LOREG) y se incorpora además una causa de incompatibilidad sobrevenida que afecta a los cargos electos (art. 6.4 de la LOREG).

En lo que ahora nos interesa, el art. 49.5 LOREG permite la interposición del recurso contencioso-electoral «a los supuestos de proclamación o exclusión de candidaturas presentadas por los partidos, federaciones, coaliciones y agrupaciones de electores a los que se refiere el art. 44.4 de la presente Ley Orgánica». El plazo que tiene la Sala Especial para la resolución del recurso es de dos días y esta decisión será firme salvo en lo que se refiere a la posibilidad de interponer el recurso de amparo electoral ante el TC, que deberá resolverlo en un plazo máximo de tres días (art. 49. 3 LOREG).

No cabe duda, pues, de que las especiales disposiciones del art. 49 LOREG en cuanto a la brevedad de plazos y la falta de un trámite independiente de prueba responden a 
la naturaleza propia del proceso electoral y, en general, son exigencias necesarias para no frustrar este proceso. A pesar de las críticas recibidas se adecuan al tipo de control de proclamación de candidaturas y candidatos para el que fueron previstas: la fiscalización de irregularidades formales que se pudieran dar en la proclamación, cuestiones, en definitiva, de legalidad procedimental. Ahora bien, esta articulación del art. 49 LOREG ¿es la adecuada para resolver un supuesto que supera con creces una mera incorrección formal en la proclamación de candidaturas y candidatos y exige, por el contrario, la acreditación suficiente, razonada y proporcionada del siempre problemático fraude de ley?

Esta cuestión se planteó ya por vez primera en la STC 85/2003, en uno de los votos particulares, y se ha reiterado a lo largo de la ya dilatada aplicación del art. 49 LOREG, en relación con el art. 44.4 LOREG, incluido en el caso Bildu .

En realidad, nos encontramos ante una paradoja. El ordenamiento electoral con el fin de que el proceso electoral se desarrolle con todas las garantías establece, en lo que se refiere a la proclamación de candidatos y candidaturas, un recurso electoral. Por la naturaleza del proceso electoral este recurso se formula con restricciones en el ejercicio de las garantías procesales de defensa y en el ejercicio del principio de contradicción. Bajo estas restricciones se tiene que probar que Bildu es la continuidad fraudulenta de un partido ilegal. La brevedad del plazo es también necesaria porque para garantizar aún más el proceso electoral se establece la garantía extraordinaria del recurso de amparo electoral, que también se debe dirimir en tiempo breve para no malograr el proceso.

En definitiva, a medida que se establecen más garantías judiciales del proceso electoral (recursos) menos garantías procesales de defensa y de contradicción tienen los candidatos. Si a esto se suma que en ese tiempo se dirime una cuestión de gran complejidad, donde entran en juego derechos de trascendencia como los de participación política y que se trata de decisiones jurisdiccionales de gran calado político, necesitadas más que nunca del sosiego y la reflexión, entonces, no hay duda de que los problemas de constitucionalidad del art. 49.5 LOREG en relación al art. 44.4 LOREG se acentúan.

Lógicamente el Tribunal no podía mantenerse totalmente ajeno a las «perversiones» que comporta el art. 49 LOREG. Por ello, el TC finalmente dicta una sentencia interpretativa/aditiva y una sentencia de recomendación al legislador, que consigue salvar la constitucionalidad del precepto. Así, en primer término, para conciliar el art. 49 LOREG con las exigencias constitucionales de los principios de contradicción e igualdad de armas prevé un trámite específico de alegaciones en el proceso y permite acompañar los elementos de prueba pertinentes en el proceso a quo ${ }^{8}$.

No obstante, ante estas deficiencias, el Tribunal se ve compelido a dar un paso más y toma una decisión de mayor trascendencia. El recurso de amparo electoral deja de ser sólo un recurso de amparo ordinario con especialidades en cuanto a su fugacidad y tramitación y se permite que en sede constitucional las partes puedan formular nuevas alegaciones y proponer nuevas pruebas?

7 Vid. FJ 2 de la STC 62/2011.

8 STC 85/2003, FJ 11.

9 STC 85/2003, FJ 9 y especialmente los FFJJ 5, 6 y 12 de la STC 99/2004, y FJ 5 de la STC 68/2005. 
De cualquier forma, en cada Sentencia el TC se muestra más crítico hasta que finalmente en la STC 68/2005 acaba haciendo una llamada al legislador para que proceda a reformar el art. 49 LOREG $^{10}$. El legislador, no obstante, no ha aprovechado la reforma de 2011 para atender la petición del Alto Tribunal.

Esta problemática constitucional del art. 49 LOREG también ha estado presente en el caso Bildu. Ante las alegaciones de indefensión en la Sala Especial por los exiguos plazos del art. 49 LOREG, la Sala decidió ampliar un día el plazo para que la Coalición pudiera completar sus alegaciones. Así mismo, ante el Constitucional, Bildu alegó que el plazo le impedía ejercitar su derecho de defensa y a un proceso con todas las garantías (ex art. $24 \mathrm{CE}$ ), por lo que el TC también amplió su plazo, lo que provocó que el TC dispusiera sólo de un día para la deliberación y el fallo. Igualmente reveladoras de las dificultades que plantea el precepto son las afirmaciones del voto particular conjunto a la STS de 1 de mayo de 2011, en cuanto a la valoración del elemento de conexión subjetiva de los candidatos con Batasuna: «Solamente añadiremos que en las alegaciones de la parte recurrida se han denunciado más de un centenar de errores en el análisis de las listas hecho por el Fiscal (siguiendo el Informe de la Guardia Civil incorporado a autos) que, dadas las limitaciones procedimentales de este recurso contencioso-electoral, esta Sala no está en condiciones de afirmar si efectivamente todos ellos son o no errores... Algunos de esos errores — si es que lo son — resultan especialmente llamativos» (las cursivas son nuestras).

No hay duda de que cuando de lo que se trata es de determinar un fraude de ley en el que se ven implicadas un número tan elevado de candidaturas (casi doscientos sesenta), la brevedad del plazo en el que el Tribunal tiene que decidir sobre la aplicación conforme a la Constitución del art. 44.4 LOREG, conlleva una merma de las garantías procesales que el recurso de amparo no puede diluir. Todo ello sin olvidar, como ha ocurrido en este caso, los costes que esta decisión del TC conlleva.

\section{LA DOCTRINA CONSTITUCIONAL EN MATERIA DE SUCESIÓN FRAUDULENTA DE PARTIDOS POLÍTICOS ILEGALIZADOS Y DISUELTOS (ART. 44.4 LOREG). SU APLICACIÓN AL CASO BILDU}

El art. 44.4 LOREG, en su redacción dada por la LO 3/2011, establece que «en todo caso, los partidos políticos, las federaciones o coaliciones de partidos, y las agrupaciones de electores no podrán presentar candidaturas que, de hecho, vengan a continuar o suceder la actividad de un partido político declarado judicialmente ilegal y disuelto, o suspendido». Para determinar la continuidad fraudulenta en estos términos el art. 44.4 LOREG establece un elenco de parámetros. La STC 85/2003, de marcado carácter interpretativo, no sólo determinó cómo debía interpretarse constitucionalmente el supuesto de hecho y el sentido del art. 44.4 LOREG, sino que además construyó una doc-

10 FJ 4 de la STC 68/2005. Sobre esta cuestión vid IGLESIAS BÁREZ, M, La ilegalización de partidos políticos en el ordenamiento jurídico español, Comares, 2008, págs. 312 y ss. 
trina acerca de cuál era la interpretación constitucionalmente conforme de estos criterios de sucesión fraudulenta.

Los parámetros que acreditan la sucesión en fraude de ley, según el art. 44.4 LOREG, son: 1. El criterio orgánico-funcional de naturaleza objetiva (similitud sustancial de su estructura, organización y funcionamiento). 2. El criterio personal, de naturaleza subjetiva (similitud sustancial de las personas que los componen, rigen, representan o administran las candidaturas). 3. El criterio financiero-material (procedencia de los medios de financiación o materiales). 4. Un criterio abierto: «o de cualesquiera otras circunstancias relevantes que, como su disposición a apoyar la violencia o el terrorismo, permitan considerar dicha continuidad o sucesión» ${ }^{11}$.

\section{Elemento subjetivo. La conexión relevante de las personas que componen, rigen, representan o administran las candidaturas con los partidos ilegalizados}

La STS de 1 de mayo de 2011 pone de manifiesto que los elementos subjetivos de prueba en el Caso Bildu carecen de importancia y que, por tanto, no van a tener relevancia para el fallo $\left(\mathrm{FJ} 10^{\circ}\right.$ ). No se consigue acreditar, pues, que existan elementos de conexión suficientes entre los candidatos, especialmente entre los denominados candidatos independientes, y los partidos ilegalizados. No obstante, la falta de este criterio de sucesión fraudulenta no puede ser determinante a la hora de desechar la existencia de una trama defraudatoria. Por una parte, el elenco del art. 44.4 LOREG no responde a la idea de una lista cerrada, sino que como es posible colegir del último criterio, para probar el fraude se pueden utilizar «cualesquiera otras circunstancias relevantes» que tengan la entidad suficiente para acreditar el fraude; pero es que además, la propia doctrina del TC reconoce que aunque en principio la convicción judicial del fraude deberá ser acreditada mediante una concurrencia de elementos probatorios (objetivos, subjetivos...), no obstante, « habrá de estarse a cada caso para precisar si es suficiente con la demostración de un elemento de continuidad financiera o si se impone la concurrencia de un elemento de continuidad personal... Lo decisivo, en cualquier caso, es que los criterios acreditativos utilizados abonen la convicción fundada de que estamos en presencia de una sucesión fraudulenta» (STC 85/2003, FJ 26, en el mismo sentido, SSTC 99/2004, FJ 16, y $68 / 2005$, FJ 11). El elemento subjetivo es, pues, un elemento más y en ningún momento

11 En este sentido, la Sala Especial en las SSTS de 3 de mayo de 2003 (FJ 2) en el caso de la Plataforma $\mathrm{AuB}$ y otras agrupaciones de electores, considera como circunstancias relevantes, entre otras: la denominación, las siglas y los símbolos expresados en la presentación de la candidatura, la posible participación o contribución de los partidos políticos disueltos en la promoción de la agrupación de electores, la posible participación en la elaboración o diseño del programa que se haya podido avanzar por los organizadores en relación con la futura actividad política de la candidatura propuesta. Puede acudirse también a los elementos de prueba mencionados en el artículo 9.4 de la LOPP: «el examen de las resoluciones, documentos y comunicados de la agrupación, de los actos públicos y convocatorias ciudadanas, las manifestaciones, actuaciones y compromisos públicos de los promotores de la agrupación o de los candidatos, así como de las actitudes significativamente repetidas de aquellos (promotores de la agrupación) o de éstos (candidatos). Serán igualmente tomadas en consideración por idéntica razón las sanciones administrativas y las condenas penales por delitos tipificados en los títulos XXI a XXIV del CP impuestas a unos y otros». 
un elemento necesario e imprescindible para probar el fraude de ley. De hecho el TC en el caso de la agrupación de electores Aukera Gutziak rechazó los elementos de prueba de naturaleza subjetiva «sin que por ello padezcan en su consistencia los juicios de valor deducidos de las pruebas de naturaleza objetiva» (STC 68/2005, FJ $14^{\circ}$ ) y que sirvieron por sí solos para que el TC confirmara la decisión de la Sala Especial de anular las candidaturas de la agrupación electoral.

Otra cuestión diferente es la valoración que hace la Sala Especial de la inexistencia de esos vínculos entre los candidatos de Bildu y los partidos ilegalizados. En este sentido, la Sala se hace eco de la interpretación que realizan tanto el Abogado del Estado como el Ministerio Fiscal en el sentido de que la falta de elementos subjetivos constituiría una prueba indiciaria del fraude y de los esfuerzos de ETA / Batasuna por sortear la legalidad $\left(\mathrm{FD} 10^{\circ}\right)^{12}$. No cabe duda de que esta inferencia no es constitucionalmente admisible. El hecho de que no aparezcan elementos de conexión subjetiva tiene como explicación plausible una estrategia de ETA / Batasuna para sortear la ilegalización, pero en ningún momento la explicación puede convertirse sin más en un indicio de la existencia de tal conexión. Por ello coincidimos con el TC cuando afirma que «el Estado de Derecho y, en concreto, las exigencias del proceso debido no consienten, en modo alguno, que la inexistencia de indicios adversos al ejercicio de un derecho fundamental se constituya, invertido su sentido, en argumento para obstaculizar su ejercicio» (STC 62/2011, FJ 7).

Otra consideración distinta es la valoración que merezca una coalición en la que se da una abrumadora presencia de candidatos independientes en las listas, frente a los candidatos de EA y Alternatiba, y la posición privilegiada que además ocupan los independientes en las listas. Pero esta circunstancia no está relacionada en modo alguno con la acreditación del elemento de conexión subjetiva, sino con la desnaturalización de la coalición de partidos y que constituiría, en todo caso, un indicio objetivo de la existencia de una trama defraudatoria.

\section{Elementos objetivos}

A continuación se da cuenta de las pruebas de carácter objetivo ${ }^{13}$ más relevantes de las que se sirve la Sala Especial para acreditar que existe una trama defraudatoria por medio de la cual BIDU sería la nueva veste jurídica que ha instrumentalizado Batasuna para participar en las elecciones de 2011: documentos, declaraciones públicas y noticias de prensa no desmentidas, comunicados, cartas, conversaciones telefónicas intervenidas legalmente, reuniones, programa lectoral y la composición de las listas electorales.

Documentos: 1. El documento de ETA de diciembre de 2008 «Herri Antolatuaren Estrategia Independentista Baterantz» (Hacia la estrategia independentista de la nación

12 A favor de esta interpretación se muestra también el voto particular de M. ARAGÓN (punto 5) a la STC 62/2001.

13 Estos elementos no harían referencia al primer criterio que enumera el art. 44.4 LOREG y que se centraría en la similitud sustancial de la estructura, organización y funcionamiento entre las dos formaciones políticas, sino a un conjunto variado de pruebas objetivas, es decir, ajenas a la conexión de los candidatos con los partidos ilegalizados y disueltos y que, por tanto, se encontrarían en aquellas circunstancias relevantes de las que habla el art. 44.4 LOREG en su último apartado. 
organizada. La estrategia nacional como motor del proceso de liberación). Fue intervenido al responsable del aparato político de ETA, con ocasión de su detención en abril de 2009. En este documento ETA aboga por crear una «alianza independentista» con otros agentes políticos y sociales ${ }^{14}$. 2. «Proceso Democrático. Reflexión sobre la alternativa para la solución democrática del conflicto político y para el reconocimiento de Euskal Herria». Es un documento que la Sala Especial atribuye a ETA y está fechado en agosto de 2009. Es intervenido por la Guardia Civil en un registro, en abril de 2010, en un despacho de abogados. Recoge la estrategia de ETA en relación al Estado español, a otros partidos políticos y donde se apunta ya la necesidad de llegar a un acuerdo con EA, acuerdo en el que ETA se reserva un papel principal en este proceso de acumulación de fuerzas políticas independentistas ${ }^{15}$. 3. El documento de ETA Earen Proposamenaz II.RTF» (Qué Podemos ofrecer a EA). Carece de fecha. Este documento fue incautado en abril de 2009 con motivo de la desarticulación de la estructura de ETA Halboka. Por una parte, propone una alianza con EA, de la que afirma que «una coalición así abriría muchas puertas» y, por otra, da instrucciones a la coalición de cómo deberían realizar el rechazo a los atentados terroristas en el caso de producirse. 4. Comunicado de ETA de abril de 2011 difundido por el Diario Gara, donde se publican varias páginas del Zutabe 113 de ETA, fechado en abril de 2011, en el que se señala que el último «alto el fuego» ha tenido como objeto favorecer el desarrollo del «Proceso Democrático», especialmente en lo referente a la acumulación de fuerzas. ETA se felicita por la evolución positiva de la acumulación de fuerzas, que se ha materializado con la firma de un «acuerdo estratégico entre las fuerzas independentistas». 5. Documento «BTGNari komunikazioa orokerra 0906/0609 comunicación general al BTGN», que contiene unas consideraciones sobre el intento de colaboración que hubo con EA para las elecciones al Parlamento europeo de 2009 y en las que se deja claro que es una estrategia frente a la ilegalización. 6. El denominado Akordio Elektoralerako Oinarriak (Bases para el acuerdo electoral. Marco Teórico del acuerdo) que aparece suscrito por Batasuna y está fechado en noviembre de 2010. Tiene como objetivo abrir una fase de diálogo con vistas a un acuerdo electoral con EA y Aralar para las elecciones de 2011 a partir de una serie de criterios, destacando la discreción total sobre el proceso negociador por parte de los tres promotores, el deseo de que antes de diciem-

14 En el documento se declara la intención de «impulsar una convergencia entre los diferentes agentes independentistas. Para ello hay que crear una coalición político institucional basada en la iniciativa Euskal Herria Bai...». Euskal Herria Bai es una coalición de los partidos políticos franceses Batasuna, Eusko Alkartasuna y Abertzaleen Batasuna, que se formó para concurrir conjuntamente en las elecciones legislativas francesas de 2007 y que se ha mantenido desde entonces.

15 «Hay que realizar una alianza política con Eusko Alkartasuna, el cual debe conocer un gran nivel de su desarrollo antes del Proceso Democrático. Los objetivos de esa alianza serían distintos: —Establecer en el debate político una imagen fuerte del nacionalismo-independentista en las correlaciones de fuerza. Electoralmente ser demostrativo de eso en algunas elecciones. —Fijar un aliado táctico-estratégico entorno al proceso — Aparecer como extremo para hacer frente a la ilegalización y a la ofensiva fascista española - Causando dentro del independentismo el renacimiento del nacionalismo: fulminar a Aralar y causar desgaste político electoral a PNV. - Ofrecer una imagen de la acción unitaria general de los independentistas.» En otro pasaje se afirma que «Esa Estrategia de Negociación sólo lo conocerán la Organización, la Dirección de Batasuna y los interlocutores para la negociación y con qué acuerdo conseguido saldremos», «Sin «cogollito», sin dirección paralela, sin cocinillas internas: la dirección del Proceso está en la Organización y en la Dirección de Batasuna (Zuzendaritza Batasuna)». 
bre debería estar resuelta la opción para el acuerdo y que Batasuna entraría en el reparto de cargos cualquiera que fuera su situación legal ${ }^{16}$. 7. Documento «Planificación Política. Curso 2010-2011». Acuerdo Lortu Arte. Es un acuerdo suscrito en junio de 2010 entre EA y la denominada Izquierda Abertzale en el Palacio Euskalduna de Bilbao. En su firma participó el Secretario General de EA, y en representación de la Izquierda Abertzale firmaron el acuerdo integrantes de la última Mesa Nacional de Batasuna. 8. El Acuerdo «Euskal Herria Ezkerretik / Euskal Herria desde la izquierda». Data de enero de 2011 y fue suscrito por Batasuna, EA y Alternatiba y presentado en un acto público ${ }^{17}$. 9. «Herri Akordia». Metodología Básica. No consta la fecha ni tampoco se identifican los firmantes del acuerdo. Sólo se especifica que se trata de tres formaciones políticas. Fué publicado por diferentes medios de comunicación y localizado por la policía en un control antiterrorista. En el documento se establecen las condiciones del acuerdo electoral en materia de programas, elaboración de las listas electorales y el cumplimiento del acuerdo ${ }^{18}$. 10. Acta de ETA de una reunión celebrada entre ETA y EA, en la que se habla de la posibilidad de un intento de colaboración con Eusko Alkartasuna de cara a las elecciones autonómicas y europeas de 2009, que no se llevó a cabo.

Declaraciones públicas y noticias de prensa no desmentidas: Entre ellas se puede destacar las notas de prensa que se publicaron en relación al documento Lortu Arte. Así, en el Diario Vasco se dice en titular que «Batasuna y EA abren el escenario para que la vía política arrincone la violencia»; el Diario de Navarra tituló «La izquierda «abertzale» y EA firman su alianza sin una condena de ETA» y en el diario Gara se afirmó que «La izquierda abertzale ofrece a Aralar y EA ir juntos al Parlamento navarro». De la misma forma en la demanda del Ministerio Fiscal ante la Sala Especial se recogen un conjunto de declaraciones públicas tanto de representantes de EA y Alternatiba, como de miembros de Batasuna y otros partidos ilegalizados. De estas declaraciones se deduce la disposición de EA, Alternatiba y Batasuna a firmar acuerdos políticos, así como la materialización de éstos, incluso en el caso de que Batasuna continuara ilegalizada ${ }^{19}$.

16 En él se hace constar la necesidad de «convenir previamente una elección común sobre los derechos de los representantes de Batasuna». Se añade explícitamente: «El reparto de cargos que se hace en las listas se llevará hasta el extremo, cualquiera que sea los pasos que da el Estado sobre la legalización. Batasuna gestionará los asientos que le corresponden a Batasuna, cualquiera que sea la situación legal».

17 En el Informe de la Guardia Civil se señala que, antes del indicado acuerdo, el Barne buletina de Batasuna de enero de 2011 ya anunciaba su celebración y que la formación ilegalizada participaría en la firma del mismo.

18 A tal efecto, se indica que cada partido remitirá el «Programa Básico» a sus responsables en los pueblos «donde tenga intención de sacar lista». Cuando los responsables locales de las tres formaciones políticas reciban el «Programa Básico», el documento prevé la organización de una reunión común de todos ellos, donde cada partido propondrá a través de esos representantes los «puntos/temas/proyectos/propuestas» en torno al «Programa Básico». En cuanto a la conformación de las listas electorales se indica que "para distribuir esa cifra de voto entre nosotros se concretará en función del resultado de las eleccciones de años anteriores o del porcentaje pactado en el pueblo. Una vez concretada la cifra del voto que le corresponde a cada partido de la localidad, el orden de los candidatos se establecerá según la Ley D’ Hont siempre tomando como base la proporcionalidad mencionada». Por último, el Acuerdo contempla y regula la necesidad de adoptar medidas que garanticen un funcionamiento y una línea unificada para el desarrollo del acuerdo programático así conseguido.

19 Destacamos por su interés sólo una muestra de las mismas, advertiendo que en la demanda del Ministerio Fiscal ante la Sala Especial se registran más de una docena de declaraciones. Entrevista en el diario Gara al Secretario General de EA, el 26 de marzo de 2011, donde contesta éste: «A través de una apuesta comprometida con los acuer- 
Comunicados: En marzo de 2011, EA y Alternatiba difundieron un comunicado conjunto en el que manifestaron, que «las dos formaciones, firmantes junto a la Izquierda Abertzale del Acuerdo Euskal Herria Ezkerretik, consideran necesario presentar a la ciudadanía vasca un nuevo sujeto electoral soberanista y de izquierdas que aglutine voluntades más allá de siglas y coyunturas electorales, y que haga posible el inicio del cambio en nuestro país», por lo que «anuncian que comienzan a trabajar para presentar una oferta que represente al conjunto del soberanismo de izquierdas, sin vetos ni exclusiones». Y, finalmente en abril de 2011, se produjo un acto político para la presentación de la Coalición Bildu, formada por EA, Alternatiba, Araba Bai y la agrupación «Herritarron Garaia / La hora de los ciudadanos», además de «independientes», anunciando que en unos días se harían publicas las candidaturas para las elecciones municipales y forales. Apenas unos días después de este comunicado y de que la Sala Especial prohibiera la inscripción de Sortu en el Registro de Partidos Políticos, mediante el Auto de 30 de marzo de 2011, tuvo entrada en la Junta Electoral Central la documentación acreditativa de la constitución de la Coalición electoral «Bildu-Eusko Alkartasuna (EA)/Alternatiba Eraiktizen».

Cartas: De entre las cartas destacamos una, la de una destacada militante de Batasuna a un preso de ETA, fechada en diciembre de 2010, donde la remitente dice: «... tenemos montado un foro de debate donde se supone habrá aportaciones para mejorar lo que presentamos y después con todo ello empezar a elaborar el herri programa ... ahora el peso lo llevamos nosotros, sólo tenemos que trabajar doble primero preparándolo con EA. Estos no están acostumbrados al trabajo de calle y hay que ponerles las pilas pero bueno poco a poco irán aprendiendo digo yo».

Conversaciones telefónicas intervenidas legalmente: De las conversaciones se deduce que personas relacionadas con Batasuna u otras formaciones ilegalizadas buscan candidatos para las elecciones de 2011, y que además esos candidatos tienen que tener la condición de estar «limpios», es decir, no deben guardar conexión alguna con ETA/Batasuna. Al mismo tiempo en las conversaciones se pone de manifiesto las dificultades que tienen para encontrar a candidatos no contaminados y las presiones para que los posibles candidatos formen parte de las listas electorales, y como los miembros de Batasuna elaboran las listas menospreciando a EA e incluso sin contar con este partido político ${ }^{20}$.

dos estratégicos firmados en estos dos últimos años, pero sabiendo que su traslación al ámbito electoral no va a poder ser directa, porque la marca de la izquierda abertzale no va a poder estar. Pero hay un compromiso para llevar adelante lo firmado en esos acuerdos estratégicos. [...]. En Nafarroa ya estamos dando los primeros pasos. A día de hoy no puedo decir cuál será la fórmula concreta, si va a tener un nombre o cual será, pero apostamos por un ente aglutinador. Tras la sentencia del Supremo, Sortu no podrá tomar parte porque no será legal, pero tenemos que seguir con el esfuerzo aglutinador y sabemos que hay un sector de esta sociedad que está dispuesto a formar parte de esa suma» En enero de 2011 se entrevista en una emisora de radio al portavoz de Alternatiba: [¿Alternatiba podría llegar a un acuerdo electoral con Batasuna?] En Alternatiba claro que si se daba ese debate político y se daban las condiciones oportunas sería factible explorar las posibilidades del acuerdo. Por el momento hemos firmado un acuerdo político, una condición indispensable para que pueda haber concurrencia conjunta electoral, que no descartamos en un futuro» Un dirigente de Batasuna en una entrevista en la web www.ezkerabertzalea.info destaca que $[\ldots .$.$] «el$ acuerdo estratégico entre la izquierda aberzale y EA, y el acuerdo de ambos con Alternatiba para una propuesta soberanista y de cambio social, esta abriendo una correlación de fuerzas nueva y determinante para profundizar en el proceso democrático y avanzar en un proceso de negociación desde una nueva posición de fuerza del soberamismo e independentismo vasco».

20 En conversaciones entre determinados miembros de Batasuna en la que se alude a terceras personas para ser candidatas y cómo se pone especial atención al hecho de que no estén «pilladas». Otro ejemplo es la con- 
Reuniones: Cabe citar en este punto las mantenidas, por ejemplo, entre el «hauteskunde taldea/equipo electoral» de Batasuna y comités locales de EA en marzo de 2011. En esta reunión participaron destacados responsables de Ekin y Batasuna, ex concejales de Euskal Herritarrok y candidatos por Eusko Abertzale Ekintza en las elecciones municipales de 2007. Esta reunión tuvo continuidad con los mismos participantes días después, también en las sedes de EA.

Programa electoral: El 19 de enero de 2011, en un acto político en San Sebastián, miembros del partido ilegalizado ANV, entre otros, presentaron los ejes a seguir en la elaboración del «Herri programa» para las elecciones municipales y forales de mayo de 2011.

Composición de las listas electorales: En el FD $3^{\circ}$ de la STS de 1 de mayo de 2011, la Sala Especial, recogiendo datos suministrados por el Ministerio Fiscal, pone de manifiesto que «el porcentaje de candidatos supuestamente independientes que figuran en las listas es extraordinariamente elevado, alcanzando concretamente el $100 \%$ de independientes en las candidaturas del $51 \%$ de los municipios de Guipúzcoa, el 35\% de los municipios de Araba y el $36 \%$ de los de Vizcaya, teniendo en cuenta, además, que en Araba concurre en la coalición con Araba Bai...Que, en cualquier caso, el número de candidatos supuestamente independientes incluidos en las listas suponen el $75 \%$ o más del total de candidatos en aproximadamente un 92\% de los municipios de Guipúzcoa, el $45 \%$ de los de Araba y el $70 \%$ de los de Vizcaya, con la misma consideración que hemos efectuado anteriormente respecto de Araba. En Navarra el porcentaje de municipios que superan esa cifra es del 91'84\%... Otro dato de interés es el número de municipios en el que los independientes ocupan todas las posiciones que supuestamente permitirían resultar electo. Ello ocurre en 35 municipios de Guipúzcoa, 9 municipios de Araba y 48 de Vizcaya».

De los elementos objetivos de prueba aportados, la Sala en su STS de 1 de mayo de $2011(\mathrm{FD} \mathrm{12}$ ) llega a la conclusión de que «en definitiva, y salvo que se quiera mantener formalmente las apariencias a riesgo de hacer la realidad ininteligible, la coalición electoral Bildu responde a lo que fue el designio inicial del Acuerdo suscrito entre Batasuna, Eusko Alkartasuna y Alternatiba: una coalición que permite a Batasuna/ETA volver a la presencia institucional en las Administraciones territoriales de acuerdo con sus estimaciones de electorado y con garantía de autonomía operativa, aun integrada en la Coalición». En su opinión, no sólo ETA/Batasuna tiene una trayectoria fraudulenta para presentarse a las elecciones, que debe ser valorada como indicio a tenor de lo que dispone la STC 99/2004 $\left(\mathrm{FJ} 15^{\circ}\right)$, sino que a través de los diversos documentos y declaraciones se expone cómo ETA/Batasuna tenía intención de presentarse a las elecciones de 2011 de la mano de partidos políticos como EA y otros que le sirvieran como «acumulación de fuerzas». Al tiempo considera que esa intención se materializó en diversos Acuerdos firmados donde incluso como en el documento Herri Akordia se dispone el reparto de candidatos en las listas electorales, reparto que se siguió a grandes rasgos en las listas de la Coalición Bildu. A esta conclusión contribuyen también las conversaciones telefónicas aportadas donde se mani-

versación sostenida entre uno de los máximos dirigentes de Batasuna, en la que van repasando la lista de los primeros candidatos a uno de los Ayuntamientos y cómo se felicita de que en las mismas se incorporen «sus» candidatos. En otros lugares, como Navarra han sido dos miembros significados de la formación ilegalizada EAE/ANV, los que, por sí solos y sin haber tenido negociación alguna con EA, han conformado las listas de esta coalición para dicho Ayuntamiento. 
fiesta el manejo que hace Batasuna de las listas electorales. La trama se deduce también, por otra parte, de las propias condiciones de la Coalición, y haciendo suya la opinión del Ministerio Fiscal declara «que bajo la apariencia de una coalición electoral aparece un primer aspecto sorprendente, cual es que en casi todas las candidaturas presentadas por Bildu el porcentaje de candidatos independientes supera ampliamente la suma de los candidatos de las formaciones políticas legalmente constituidas que la integran, lo que ya de por sí representa una verdadera desnaturalización de esta fórmula electoral de "pacto de coalición» entre partidos y federaciones que regula el artículo 44.2 LOREG»(FD $3^{\circ}$ ).

La STC 62/2011 considera que de las pruebas referidas puede deducirse razonablemente que ha habido un interés por parte de ETA/Batasuna de converger con fuerzas políticas independentistas, pero que tal interés no ha llegado a materializarse en acuerdos concretos. En realidad, «se trata de conductas ajenas, en este caso documentos ajenos, que lo único que acreditan es la referida estrategia de la organización terrorista y del partido político ilegalizado, pero no la instrumentalización de la coalición electoral al servicio de dicha estrategia» $\left(\mathrm{FJ}^{\circ}\right)$. En concreto, entiende que algunos de los acuerdos referidos y que la Sala Especial atribuye a Batasuna, en realidad, están suscritos por la Izquierda Abertzale, EA y Alternatiba pero no por Batasuna, como es el caso del acuerdo «Euskal Herria Ezkerretik/Euskal Herria desde la Izquierda», «Lortu-Arte», o del documento «Herri Akordioa. Metodología básica», que en concreto no aparece suscrito por ninguna fuerza política y sobre el que Bildu, por otra parte, ha negado tener conocimiento, además de que en las informaciones periodísticas aparece referido a la Izquierda Abertzale, no a Batasuna (FJ $9^{\circ}$ ). En el mismo sentido considera que en sí mismos nada acreditan el designio defraudador el documento «BTGNari Komunikazia orokerra 0906/0609 comunicación general al BTGN», pues fue un intento de colaboración para las elecciones al Parlamento europeo de 2009, que finalmente no llegó a consumarse. Califica, por otra parte, de excesivamente débiles o irrelevantes las cartas intervenidas de una militante de Batasuna a un preso de ETA «en la que se hace una vaga y genérica referencia a Eusko Alkartasuna en relación con la elaboración del herri programa» o a la declaración de otro miembro de ETA ante los tribunales en la que reconoció como elaborado por él mismo un escrito en el que se alude a una asamblea que se llevó a cabo en Vitoria y en la que, según su autor, se dio cuenta a la base social del acuerdo alcanzado por Eusko Alkartasuna-EA y Batasuna sin más precisión» $\left(\mathrm{FJ} 9^{\circ}\right)$. En la misma línea, el TC considera que en las declaraciones públicas se hace referencia a la Izquierda Abertzale, pero no a Batasuna. En relación a las conversaciones telefónicas, «en ocasiones, no se identifica a los comunicantes, en otras se los identifica como miembros de Batasuna pero no se sabe si todavía lo son. En la mayoría de los casos lo que revelan las conversaciones es únicamente la dificultad a la hora de elaborar las listas electorales» $\left(\mathrm{FJ} 10^{\circ}\right)$. De las reuniones, «se conoce sus participantes pero no el contenido de las mismas» o se «afirma que los participantes de Batasuna eran los responsables del equipo electoral y del elevado número de candidatos independientes, no demostrado el elemento subjetivo de conexión, no puede transmutarse en un elemento objetivo de sucesión fraudulenta» $\left(\mathrm{FJ} 10^{\circ}\right.$ ). Finalmente, el TC tampoco acepta como prueba válida un informe de la Guardia Civil por el que se incorpora, ya en la fase del recurso de amparo, un acta de ETA de una reunión celebrada entre ETA y EA, ya que en ella se habla la posibilidad de un intento de colaboración entre la Izquierda Abertzale y EA de cara a las elecciones autonómicas y europeas de 2009, que no llegó a consumarse (FJ 11). 
Debemos recordar que es doctrina consolidada del TC que en los casos de fraude y levantamiento del velo, como es el supuesto de sucesión fraudulenta de partidos ilegalizados, se tendrá en cuenta que "para alcanzar esta conclusión la Sala ha debido superar las dificultades inherentes al descubrimiento de toda trama defraudatoria y se ha basado en un material probatorio constituido tanto por pruebas directas como indiciarias» (STC 112/2007, de 10 de mayo, FJ 8).

Además, continúa el Tribunal, la valoración del fraude ha de depender de una apreciación conjunta de la prueba (STC 85/2003, de 8 de mayo, FJ 29; doctrina reiterada, entre otras, en las SSTC 68/2005, de 21 de marzo, FJ 11; 126/2009, de 21 de mayo, FJ 7). Por otra parte, el TC considera que «no se puede pretender de esta Sala la revisión de las pruebas practicadas en el proceso, ni la de la valoración judicial que las mismas han merecido del Tribunal Supremo, pues en otro caso, con infracción del principio de exclusividad de la jurisdicción ordinaria (art. 117.3 CE), incurriríamos en un claro exceso de nuestra jurisdicción constitucional»y, por tanto, «ha de descartarse en este contexto la valoración individualizada y singular de cada una de las pruebas llevadas al proceso,... pues esa pretendida valoración individualizada de cada una de las pruebas es tarea que no nos corresponde, imponiéndose, por el contrario,... el enjuiciamiento global, sintético y de conjunto de la prueba» (por todas, STC 31/2009, de 29 de enero, FJ 4).

La STC 62/2011, de 5 de mayo, comienza apartándose de su doctrina anterior, que le exigía la valoración conjunta de la prueba practicada y no sólo entra a valorar la validez de las pruebas, validez que por otra parte, no ha sido puesta en duda ni siquiera por la propia Coalición Bildu en el proceso de amparo; sino que además considera que su labor «tampoco puede lógicamente excluir su examen individualizado, o el de alguno de ellos, cuando resulte necesario a fin de despejar las posibles dudas que pueda constitucionalmente suscitar su validez, solidez o calidad» (FJ $4^{\circ}$ ). No cabe duda de que en el Caso Bildu el TC parece olvidar en parte el papel que le corresponde en este tipo de procesos, que es el de verificar si la valoración que ha efectuado la Sala Especial ha acreditado de manera suficiente y motivada la existencia de una trama defraudatoria. Es decir, determinar si la valoración de la Sala viola el art. 23.2 CE por ser excesivamente abierta e irrazonable ${ }^{21}$. Valorar de forma individual y singularizada cada una de las pruebas ${ }^{22}$, no realizar una valoración de conjunto, teniendo en cuenta además que estamos ante un supuesto fraudulento donde el levantamiento del velo exige de la utilización de pruebas in-

21 Ya anunciaba la STC 135/2003 que «... el control constitucional de la racionalidad y solidez de la inferencia en que se sustenta la prueba indiciaria puede efectuarse tanto desde el canon de su lógica o cohesión (de modo que será irrazonable si los indicios acreditados descartan el hecho que se hace desprender de ellos o no llevan naturalmente a él), como desde el de su suficiencia o calidad concluyente (no siendo, pues, razonable, cuando la inferencia sea excesivamente abierta, débil o imprecisa), si bien en este último caso el Tribunal Constitucional ha de ser especialmente prudente, puesto que son los órganos judiciales quienes, en virtud del principio de inmediación, tienen un conocimiento cabal, completo y obtenido con todas las garantías del acervo probatorio...».

22 Sobre la atomización de la prueba vid el voto particular de HERNANDO (puntos 1 y 2) y de Arribas a la STC 62/2011. 
diciarias valoradas conjuntamente, es sin más una violación del principio de exclusividad de la jurisdicción ordinaria (art. 117.3 CE) ${ }^{23}$.

Está probada la trayectoria defraudatoria de ETA/Batasuna desde 2003 y este dato es reconocido y avalado como indicio por la STC 112/2007, FJ 8. Por otra parte, existen una serie de documentos de ETA y Batasuna de los que se puede deducir razonablemente que tenían la pretensión de construir un «bloque soberanista» y que entre los partidos por los que se tenía un interés especial era EA; que los acuerdos que se proponían no eran meramente políticos sino que tenían también con proyección electoral, es decir, con la intención de estar en las elecciones (primero en las elecciones europeas de 2009 y más tarde en las de 2011) y que estos acuerdos eran considerados por ETA como una buena estrategia para eludir la ilegalización y, finalmente, que se mantendrían con independencia de la situación legal de Batasuna («Proceso Democrático», «Akordio Elektoralerako Oinarriak (Bases para el acuerdo electoral. Marco teórico del acuerdo). De la misma forma, se ha acreditado por la Sala Especial que esta intención cristalizó en el documento «Euskal Herria Ezkerretik / Euskal Herria desde la izquierda suscrito en enero de 2011 por Batasuna, EA y Alternatibay presentado en un acto público. Esta decisión se deduce también tanto de las declaraciones de EA y Alternatiba, como de Batasuna y que se producen en los meses previos a las elecciones locales de 2011. En el mismo sentido, del documento «Herri Akordioa. Metodologia básica» se determina que estas tres formaciones políticas habían acordado las reglas del reparto de las candidaturas en las listas electorales, tomando como criterio «la proyección de voto de la Coalición», «en función del resultado de las elecciones de años anteriores o del porcentaje pactado en el pueblo». Con este documento el TC se muestra especialmente crítico, pues no aparece firmado. No podemos olvidar que este documento fue publicado por dos periódicos y no fue desmentido en su momento por las formaciones aludidas y que además se encontró por la policía tras un control antiterrorista, pero lo más importante es que las condiciones del diseño de la Coalición en lo relativo a los programas, y especialmente en lo referente al reparto de las candidaturas fue reflejado fielmente por la Coalición Bildu ${ }^{24}$. A ello podemos unir los

23 Sobre el exceso de jurisdicción en el que incurre el TC vid los votos particulares a la STC 62/2011 de los Magistrados Aragón Reyes (punto 4), Pérez de los Cobos, Hernando y Arribas.

Vid. también CABALLERO SÁNCHEZ-IZQUIERDO, J. M., «Sentencia del Tribunal Constitucional sobre Bildu, o la consumada invasión del ámbito jurisdiccional reservado al Poder Judicial, Diario La Ley, n. 7650, 2011, DE MENDIZÁBAL ALLENDE, R, «El caso Bildu: dos grandes tribunales enfrentados, Diario La Ley, n. 7653, 2011, BLANCO VALDÉS, R., «Bildu y el etarra que ya no tenía que mentir», La Voz de Galicia, 13 de mayo de 2011.

24 Sobre los reparos jurídicos de este documento y cómo el TS los supera vid el FD $12^{\circ}$ de la STS de 1 de mayo: «La alegación no puede ser acogida por tres razones: primero, porque un acuerdo de esta índole, a través del cual se busca dar presencia electoral camuflada a un partido ilegalizado, no se hace, por principio, ni de forma pública ni mediante signos exteriores que lo identifiquen, estando además dentro de la lógica que una vez que se hace público aunque no por la voluntad de quienes lo conformaron sino porque es interceptado, estos pretendan desvincularse de él y así salvar las apariencias; segundo, porque por encima de las circunstancias coyunturales de su hallazgo por las Fuerzas de Seguridad, lo cierto es que antes de ello fue publicado en dos medios de comunicación diferentes, dándose con tal ocasión cumplidos datos sobre el contenido del acuerdo que coinciden con el texto localizado por las fuerzas policiales, sobre cuya actuación, por cierto, tampoco hay realmente razones para dudar, pues resulta una hipótesis lógica y razonable que con ocasión del control de carreteras en que se localizó, algún ocupante de los vehículos examinados arrojase dicho documento por la ventanilla justamente para evitar su incautación en su poder: y tercero, y sobre todo, porque la realidad de las cosas demuestra que las candidaturas efectivamente pre- 
datos objetivos de que EA fue expulsada de Nafarroa Bai, es decir, de una coalición de partidos independentistas, por sus contactos y acuerdos con Batasuna y que este hecho ha sido reconocido por Nafarroa $\mathrm{Bai}^{25}$. Tampoco podemos echar en el olvido el hecho de que Bildu no deja de ser una coalición electoral «atípica», donde los candidatos independientes son abrumadoramente mayoritarios frente a los candidatos de los partidos políticos, y además se hacen con unos puestos en las listas «en función de los resultados obtenidos en anteriores elecciones» (¿por qué partido?), puestos además privilegiados; y donde parece que el «invitado» de la Coalición es un partido como EA, con una larga trayectoria política. También resulta llamativo que un partido como EA con unos pésimos resultados electorales y una escasa capacidad operativa y otro como Alternatiba, recién formado, junto con unos independientes se conviertan en una eficaz maquinaria electoral capaz de presentar tan elevado número de candidaturas. No deja de resultar sorprendente la existencia de una Coalición de esta naturaleza en nuestro Estado de partidos.

Todos estos indicios pudieran quedar desvirtuados si tal y como entiende el TC existe una diferencia entre la llamada Izquierda Abertzale y Batasuna, argumento que el TC emplea en numerosas ocasiones para rechazar las pruebas. Así, el TC pone de manifiesto que la Sala Especial ha incurrido en un supuesto constitucionalmente prohibido en nuestro Derecho, el de la «democracia militante», pues en muchas de las pruebas identifica y confunde a la Izquierda Abertzale con Batasuna, lo que implica una persecución ideológica de la Izquierda Abertzale, cuando «en nuestro Ordenamiento no cabe excluir ideología alguna, ni por su contenido o sus fundamentos» (STC 126/2009, FJ $9^{\circ}$ y STC 62/2011, FJ 6). No cabe duda de que la utilización de la expresión Izquierda Abertzale desde el punto sociológico o desde la perspectiva de la ciencia política hace referencia a una corriente ideológica donde se agruparían partidos de izquierda e independentistas, donde se hallarían, pues, EA, Alternativa, Aralar e incluso la propia Batasuna. No obstante, en el contexto de la ilegalización de partidos la Izquierda Abertzale se utiliza como sinónimo de Batasuna. Por tanto, en este contexto, esta expresión tiene una densidad de significado del que carece desde otra perspectiva. No es otra a la conclusión a la que razonablemente llegamos si se consultan las notas de prensa, artículos de periódicos, documentos y declaraciones de los propios miembros de la Izquierda Abertzale y de Batasuna, que lógicamente no propondrían acuerdos con la Izquierda Abertzale si no se entendiera que la Izquierda Abertzale de la que se habla y de la que la propia EA se autoexcluye, es Batasuna ${ }^{26}$.

sentadas han seguido fielmente este plan, dado que dichas candidaturas responden en su composición y orden de presentación de los candidatos a las consignas que en dicho Acuerdo se daban...Cabalmente, si, como decimos, las listas realmente elaboradas siguen la pauta marcada por aquel acuerdo, sólo puede explicarse porque el mismo realmente existió y los partidos componentes de la coalición se sintieron vinculados por él, entre otros aspectos, en el de garantizar a Batasuna (a través del partido novedoso que hemos apuntado) la elección de cargos representativos en proporción correlativa a sus resultados electorales precedentes y a las estimaciones de voto manejadas».

25 Esta noticia es recogida por el diario Gara donde destacados dirigentes de Nafarroa Bai afirman que «EA tiene la puerta abierta para seguir en NaBai, pero ha elegido su unión con Batasuna».

26 Declaraciones de una dirigente de la Mesa Nacional de Batasuna en su intervención en la presentación del Acuerdo «Euskal Herria desde la Izquierda»: «El acuerdo que presentamos la izquierda Abertzale, Eusko Alkartasuna y Alternatiba quiere responder de manera positiva a la nueva fase que se está progresivamente abriendo el Euskal Herria». Documento de Batasuna «Clarificando la fase política y la estrategia»: «La Izquierda Abertzale debe concretar el estrategia para alinear en una dirección independentista a aquellos secto- 
En definitiva, no nos parece arbitraria ni irrazonable la conclusión de la Sala Especial de que Bildu es el nuevo disfraz jurídico del que se ha servido Batasuna para presentarse a las elecciones. Veremos a continuación si esta sospecha razonable de fraude puede ser desvirtuada por la condena que hace Bildu de la violencia.

\section{La condena de la violencia terrorista por la Coalición Bildu}

En opinión del TC esta circunstancia de la condena de la violencia terrorista por Bildu no es necesario analizarla ya que es un contraindicio que actúa sólo en los casos de sospecha de sucesión fraudulenta, y a tenor de lo decretado por el Alto Tribunal en este supuesto no se ha acreditado la materialización del fraude (FJ 12 ${ }^{\circ}$ STC 62/2011). No obstante, el TC considera, en contra de lo declarado por la Sala Especial, que en caso de ser necesario habría quedado acreditado la condena de la violencia terrorista por parte de Bildu ${ }^{27}$. En primer lugar, porque «la coalición está formada por dos partidos que, como es público, así se reconoce en la Sentencia impugnada $\left(\mathrm{FJ} 13^{\circ}\right.$ ) y se acredita con la documentación aportada por la actora, con reiteración han condenado y condenan la violencia de ETA, de modo que no hay ninguna razón para suponer que la acogida en sus listas de «independientes» se haya realizado con relevamiento u olvido de aquellas posiciones públicas» y continúa diciendo que «lo que cabe presumir es, por el contrario, que los partidos coaligados avalan y por el momento confirman la no sumisión de los «independientes» que figuran en sus listas a la organización criminal y su posición crítica frente a la violencia que practica». Por otra parte, todos los candidatos de Bildu han firmado un documento de condena de la violencia terrorista en los siguientes términos «(...) actuar utilizando única y exclusivamente vías/métodos políticos, pacíficos y democráticos, lo que lleva aparejado la oposición por todos los medios que legítimamente tenga a su alcance, a cualquier acto o actividad que suponga agresión o violación a cualquier derecho humano y al uso de la violencia para lograr objetivos políticos» (STC 62/2011, FJ 12²). Una declaración de tenor similar la ha considerado este Tribunal como suficientemente acreditativa de la condena del terrorismo» (STC 126/2009, de 21 de mayo, FJ 14)». Por último, el TC ter-

res que quieren la soberanía. Debemos asimilar que para ello hay que reunir fuerzas de diferentes áreas sociales». Rueda de prensa en Pamplona en la que una concejal en dicho Ayntamiento de ANV manifestó que «la izquierda abertzale ha dicho por activa y por pasiva que vamos a estar en las elecciones...». El diario Gara tituló «la izquierda abertzale ofrece a Aralar y EA ir juntos al Parlamento navarro» Entrevista en una emisora de radio al responsable de EA en Navarra, que manifestó que «EA no contempla otra cuestión que el enrequecimiento y la profundización en la acumulación de fuerzas, algo que quiere decir, hablando en plata, que Nafarroa Bai tenga mayor fortaleza con la incorporación de nuevas adhesiones y en este caso estamos hablando claramente de la izquierda abertzale». «Presentación del "Herri Programa 2011" por miembros del partido ilegalizado ANV, entre otros, para las elecciones municipales y forales de mayo de 2011 » y el diario Gara, en su edición del día 20 de enero de 2011, presentó esta rueda de prensa con el título «La izquierda abertzale anima a elaborar sus programas electorales».

27 En el mismo sentido, E. VÍRGALA FORURIA «El amparo a Bildu, una correcta aplicación de la Ley de Partidos», El Correo, 7 de mayo de 2011, «La izquierda abertzale ha sido consciente de que sin una ruptura con el terrorismo de ETA no iba a actuar nunca en la legalidad, y eso lo ha forzado la Ley de Partidos. Los estatutos de Sortu y los compromisos firmados por los candidatos de Bildu deben verse como una aceptación de las exigencias de la Ley de Partidos y de que ha cumplido el fin para el que fue aprobada: la exclusión de la vida política legal de los partidos que colaboran con el terrorismo». 
mina su argumento precisando que la existencia del documento de ETA Earen Proposamenaz Ii.Rtf» ("Qué podemos ofrecer a EA»), donde se establecen los términos en que ha de condenarse el terrorismo ${ }^{28}$ no autoriza a que este contraindicio pueda ser «despachado o relativizado, sin más, como «simulador» con el sólo argumento de que la propia organización terrorista habría recomendado tal crítica o condena (Fundamento de Derecho Decimotercero). De no acreditarse una objetiva colusión, nadie es responsable de comportamientos ajenos, por próximos o coincidentes que puedan ser con las conductas propias. La eficacia del contraindicio no queda sometida al dilema —insoluble para el Derecho - de la mayor o menor sinceridad del sujeto, aunque sí puede quedar condicionada a la identificación objetiva de la intención real de las declaraciones en las que el contraindicio consistiría, intención, sin embargo, que sólo puede desvelarse como contraria (y disimulada, por tanto) a partir de hechos observables y referidos o imputables al propio sujeto que pretende ejercer su derecho fundamental» (FJ 12º STC 62/2011).

Sobre la primera consideración del TC no podemos más que afirmar que se trata de un argumento falaz. En este proceso no se está discutiendo la connivencia de EA y Alternatiba con ETA, y por ello desde la Sala Especial se insiste en no dudar de la legalidad de estos partidos. Son, sin duda, dos partidos que ha condenado de forma expresa la violencia terrorista.

En relación al código de actuación firmado por todos los candidatos de Bildu, nos surgen las siguientes dudas. ¿Por qué Bildu firma este documento? No es necesario en el caso de EA y Alternatiba porque es de todos conocido que han condenado a lo largo del tiempo de forma expresa y evidente la violencia terrorista; incluso cuando EA formaba parte de Nafarroa Bai, junto a otros partidos abertzales, no se firmó un código de actuación de estas características. ¿Por qué se firma ahora cuando a la Coalición se unen lo que a simple vista son unos candidatos independientes? Una vez firmado el documento, ¿por qué se hace una referencia general a la utilización de medios pacíficos y democráticos cuando EA se había caracterizado por realizar declaraciones rotundas de condena no a la violencia en general sino a la misma ETA, incluso pidiendo su disolución? No obstante, más allá de estas dudas, debemos comprobar si esta declaración de condena de Bildu tiene la suficiente entidad para servir de contraindicio a la sospecha de una trama defraudatoria.

Es conocida ya la doctrina del TC sobre la condena de la violencia terrorista, que aunque se construye para los supuestos de las agrupaciones de electores se puede aplicar perfectamente a la sospecha de sucesión fraudulenta de un partido ilegalizado por una coalición de partidos. La condena del terrorismo constituye según el Tribunal «un contraindicio capaz de desacreditar la realidad de una voluntad de ese cariz deducida a partir de indicios suficientes» (STC 68/2005, FJ 16º). Ahora bien, no sirve cualquier fór-

28 En relación a las instrucciones «1. La coalición tiene que denunciar cualquier violación de Derechos Humanos, incluídas las ekintzas de ETA. 2. La coalición tiene que denunciar al violador principal de los Derechos Humanos y el origen de la violencia: LosEstados-Gobiernos de España (PP-PSOE) y de Francia. 3. La coalición tiene que denunciar a los violadores de segundo nivel: PNV. 4. La coalición debe pedir el «alto a la hostilidad» entre ETA y el Gobierno de España y el comienzo de las negociaciones entre ellos. 5. La coalición tiene que pedir el comienzo de la negociación entre partidos con la intención de devolverle a EH la soberanía. 6. La coalición no firmará ningún tipo de comunicado con los violadores de los Derechos Humanos (PP-PSOEPNV) para denunciar la violencia de ETA». 
mula de condena de la violencia. Para que se destruya la sospecha del fraude, la condena debe ser expresa, clara e inequívoca y referida al terrorismo ${ }^{29}$, ya que en opinión del TC «la genérica condena de la violación de los derechos humanos no alcanza a operar en este caso como contrapeso suficiente a los fines de desvirtuar tales indicios... (el terrorismo) no es lamentablemente una mera abstracción, sino una realidad concreta, perfectamente definida, ante la que no tiene el mismo valor significativo la condena genérica de la vulneración de los derechos civiles y políticos de cualquiera... y a la que es atribuible un cierto sentido de abstracción, que la condena concreta del terrorismo, que implica un referente subjetivo mucho más preciso, y que de existir constituiría el contraindicio referido en nuestra jurisprudencia» (STC 68/2005, FJ 16º. A pesar de que esta interpretación de la condena del terrorismo la formula expresamente el Tribunal en el caso de la agrupación de electores Herritarren Zerrenda (STC 99/2004) y de forma más acabada en el supuesto de la agrupación Aukera Gutziak (STC 68/2005), lo cierto es que la aplica de facto ya en la primera Sentencia que dicta en materia de sucesión fraudulenta por agrupaciones de electores. Así, en la STC 85/2003 el Tribunal estima el recurso planteado por agrupaciones que si bien tenían una similitud sustancial a nivel subjetivo con los partidos ilegalizados habían condenado y rechazado el terrorismo de ETA $^{30}$. En el mismo sentido, Aukera Gutziak realizó la siguiente declaración «Las candidaturas de la iniciativa popular expresamos nuestro compromiso inequívoco con todos los derechos y nos situamos en contra de todo tipo de conculcaciones de derechos humanos. En este sentido, defendemos el derecho que asiste a toda opción política y a quien la defienda de participar libremente en los comicios electorales». Y en declaraciones de la agrupación a «El Correo Digital», preguntada sobre un hipotético atentado de ETA dijo que «estarán en contra de todo lo que vaya en contra de los derechos civiles y políticos de quien sea» y a la Agen-

29 STC 99/2004, FJ 19: «Quebrar esa dimensión significativa del silencio con el pronunciamiento firme e indubitado frente al terrorismo y sus instrumentos es, en definitiva, lo menos que cabe demandar de quien quiere servirse de los beneficios que brinda el sistema que la criminalidad quiere subvertir».

30 Esto es realmente lo que sucedió en las elecciones municipales de mayo de 2003, entre otras con la candidatura Anueko Indarra que a pesar de contar con el $50 \%$ de sus candidatos relacionados con los partidos ilegalizados y además en los puestos relevantes $1,2,4$ y 6, cuenta entre sus candidatos con el fundador del partido político Aralar, «constituido en el año 2001 como consecuencia de un proceso de escisión de los partidos disueltos, de cuyo ideario contrario a la violencia participan los demás componentes de la agrupación». En el caso de la Agrupación Maeztuko Aukera Candidatura Independiente se afirma en el recurso de amparo interpuesto por la misma que «tanto la candidatura como todos y cada uno de sus componentes están en contra de ETA y de toda acción armada, condenándolas expresa y manifiestamente, de manera pública, cuando existe algún atentado (al efecto, se acompaña certificación del Secretario del Ayuntamiento de Arraia Maeztu del Acuerdo del Pleno de 5 de junio de 2000, adoptado por unanimidad de los asistentes, entre los que se encontraban los dos Concejales de Maeztuko Aukera Candidatura Independiente, por el que se condena el atentado mortal cometido en la persona de J.M. Pedrosa Urkiza, Concejal en el Ayuntamiento de Durango, y se expresa la solidaridad y condolencia a su familia, así como al Partido Popular, al que pertenecía)» y respecto de sus dos candidatos que en las elecciones municipales de 1999 se presentaron bajo las siglas de Euskal Herritarrok, «se afirma que se encuentran ya totalmente desvinculados de esa organización (al efecto, se aporta declaración jurada, suscrita por tales candidatos)». Lo mismo sucede con la Agrupación Herriarengatik que «aporta certificación expedida por la Secretaría del Ayuntamiento de Donamaría en la que se hace constar el Acuerdo adoptado por la Corporación con fecha 28 de julio de 1997 por el que se aprobó suscribir íntegramente el acuerdo adoptado por la Federación de Municipios y Concejos de Navarra en repulsa por el asesinato de M.A. Blanco. Este acuerdo municipal se adoptó con el voto favorable de seis concejales, al parecer, varios de ellos hoy integrantes también de la candidatura anulada», FJ 30 de la STC 85/2003. 
cia Europa Press declararon que «vamos a decir todo lo que vaya en contra de los derechos civiles y políticos de quien sea, vamos a estar en contra de todo eso». Pero todo ello no sirvió para que el TC lo considerara como contraindicio suficiente, ya que entendió que «la genérica condena de la violación de los derechos humanos no alcanza a operar en este caso como contrapeso suficiente a los fines de desvirtuar tales indicios» (STC 68/2005). También en el caso de la STC 31/2009, de 29 de enero, donde se confirma la ilegalización de ANV (FJ 12) se dice que «la postura atribuida por el Tribunal Supremo al actor frente a determinados atentados terroristas se ha basado en unos hechos, omisiones y conductas que, oportunamente constatados en el proceso, han llevado a la Sala del art. 61 LOPJ a la conclusión, razonable y motivada, de que no podía considerarse que implicaba la condena explícita y sin reservas del terrorismo. Condena del terrorismo que, en el contexto de un proceso de ilegalización de un partido al que se imputa la connivencia con ETA, hubiera sido una contraindicio suficiente para contrarrestar otros elementos de convicción razonablemente adecuados para fundamentar la convicción judicial de que un partido político actúa y se conduce como un mero instrumento de la violencia terrorista».

De lo cual podemos deducir que en la doctrina constitucional para que la condena opere como verdadera contraindicio se requiere una condena expresa e inequívoca del terrorismo de ETA, y no una condena genérica contra cualquier forma de violencia o la declaración de utilizar sólo medios pacíficos y democráticos. Lógicamente la exigencia estaría acorde con el efecto que causa: desvirtuar la sospecha de fraude, es decir, convertirse en una prueba que diluye totalmente esta sospecha.

No obstante, en la STC 126/2009 en el Caso Iniciativa Internacionalista- La Solidaridad entre los Pueblos, y aunque tampoco la condena al terrorismo era necesaria como contraindicio en este caso, el TC dio cuenta de la condena que había hecho en sede de amparo esta Coalición, condena de carácter general ${ }^{31}$ y respecto de la cual el TC consideró que serviría como contraindicio.

En el caso de Bildu, el código de actuación firmado sólo refleja una condena genérica de la violencia y la utilización sólo de medios pacíficos y democráticos para conseguir sus fines políticos. Este código no sería a nuestro juicio un contraindicio suficiente para desvirtuar la trama defraudatoria que ha sido acreditada por la Sala Especial. Tampoco lo serían, por otra parte, las declaraciones de los miembros del Bildu de las cuales, por otra parte, sólo se da cuenta de las de dirigentes de EA y Alternatiba y no constan declaraciones de condena de los candidatos independientes ${ }^{32}$.

31 «Esta parte quiere manifestar de forma clara y sin ambigüedades, que la coalición electoral 'Iniciativa Internacionalista —-La Solidaridad entre los Pueblos', así como los partidos que la integran, Izquierda Castellana y Comuner@s, nunca han utilizado medios que no sean estrictamente políticos para la obtención de sus objetivos programáticos, siendo el uso de la violencia completamente ajeno a su forma de acción y cultura política, por ello expresan un claro rechazo y condena del uso de la violencia para la obtención de objetivos políticos en el marco de un Estado democrático».

32 Voto particular de Aragón (punto 7) a la STC 62/2011. En el mismo sentido se pronuncian Hernando (punto 3), Arribas (punto 4) y Delgado (punto 3).

J. PÉREZ ROYO en su «Deseable pero no exigible». El País, 24.06.2011 afirma que «Sería deseable que ETA desapareciera y sería asimismo deseable que Bildu y Sortu exigieran a ETA que se disolviera, pero la ley no lo impone. La desaparición de ETA sería la prueba definitiva del fin de la violencia terrorista y la exigencia de 
Parece advertirse pues un cierto «overruling» en la exigencia de la condena de ETA, donde da la impresión de que de la condena expresa del terrorismo de ETA se ha pasado a una exigencia menor, a la condena generalizada de la violencia.

Esto supondría un peligroso cambio de doctrina, pues si se da a la condena una densidad de sentido tal que consigue desvirtuar por completo la sospecha del fraude, aunque haya incluso elementos de carácter objetivo que lo avalen, al menos se debería exigir, como ha ocurrido hasta ahora, que ese efecto no se pueda lograr con una simple condena genérica de la violencia.

Creemos, por otra parte, que el TC concedió demasiado protagonismo a este requisito, que no deja de ser susceptible de posibles engaños, frente a otros elementos. No hay que olvidar tampoco que ETA ha recomendado a los partidos ilegalizados incluso condenar sus propias acciones, llevar a cabo condenas genéricas y equiparar la violencia del Estado y la de ETA, con la finalidad de sortear la ilegalización, por lo que el TC debería replantearse la densidad de significado de este contraindicio y su fuerza desvirtuadora.

\section{«El riesgo para la sociedad democrática». La proporcionalidad de la anulación de las candidaturas de Bildu}

Bildu considera que la anulación de sus candidaturas en el momento de la proclamación de las candidaturas y a tenor de la reforma operada por la LO 3/2011, que permite intervenir al Estado en otros momentos del proceso electoral o bien aplicando la causa de incompatibilidad sobrevenida del art. 6.4 LOREG, constituiría un control preventivo que resultaría desproporcionado, ya que la nueva normativa disminuye el riesgo para la sociedad democrática ${ }^{33}$. Y parece que esta misma idea es asumida por el propio TC en los siguientes términos: "Conviene concluir resaltando que la simple sospecha no puede constituirse en argumento jurídicamente aceptable para excluir a nadie del pleno ejercicio de su derecho fundamental de participación política. Puede que en el futuro la sospecha quede confirmada, pero para el enjuiciamiento actual, la misma no podría conducir a un resultado limitador, so pena de dejar en lo incierto el ámbito del libre ejercicio de los derechos de participación política garantizados en el artículo $23 \mathrm{CE}$ y, con ello, el valor del pluralismo político sobre el que se fundamenta el ordenamiento constitucional del Estado democrático. La pretensión de asegurar a ultranza, mediante controles preventivos, la seguridad del Estado constitucional pone muy en primer lugar en riesgo al propio Estado constitucional. Tal pretensión resulta además desproporcionada a la vista de la panoplia de instrumentos de control a posteriori de que se ha dotado, mediante las últimas reformas legales, nuestro ordenamiento» (STC 62/2011, FJ 13º).

su disolución por parte de la izquierda abertzale, aunque no consiguiera dicho objetivo, sería la prueba inequívoca de que ya no es posible mantener la sospecha de que ETA y la izquierda abertzale son lo mismo. Desaparecerían, en consecuencia, todas las dudas acerca de la sinceridad con que la izquierda abertzale está dando cumplimiento a la Ley de Partidos».

33 La demanda de amparo en sus páginas 43 y siguientes sugiere que la modificación del art. 44.4 LOREG llevada a cabo por la Ley Orgánica 3/2011, de 28 de enero, dota «al Estado de Derecho de una capacidad de respuesta de tal intensidad e inmediatez que el riesgo para el sistema democrático español se ve sensiblemente reducido respecto de la situación anterior, cuando no totalmente desaparecido». 
Previamente, en el FJ 5 de la STC 62/2011, el Tribunal dedica tres páginas a relatar las reformas que ha llevado a cabo el legislador mediante la LO 3/2001. Este arsenal legislativo (de controles ex post) le sirve al TC para justificar que en estos procesos tiene que conducirse con un mayor rigor en la valoración de la actuación de la Sala Especial ${ }^{34}$.

El TC olvida las siguientes cuestiones: a) la legislación actual no invalida la ya existente y debe ser aplicada; b) el rigor y más en los casos donde está en juego la democracia y el valor del pluralismo político debe ser siempre el máximo. Supone esta afirmación que el TC ¿era antes menos riguroso?; c) ¿cómo es posible llevar a cabo un control más riguroso si sólo tiene un día para la valoración y fallo de 257 candidaturas?

No cabe duda de aquí de nuevo el TC se ha apartado en parte de su doctrina. Parece poner en duda la constitucionalidad de la legislación electoral que le ha permitido convalidar las decisiones de la Sala Especial durante estos ochos años de aplicación de la Ley de Partidos. Parece, pues, que el TC opta por la postura más cómoda, en espera de que si se equivoca (y tiene dudas pues habla en algunas ocasiones de que la independencia de los candidatos está probada «de momento»), se pondrán en marcha los mecanismos legales para impedir que Bildu se mantenga en las instituciones políticas. Acusa en el fondo a la Sala Especial de hacer una ilegalización preventiva cuando lo que él propone es una especie de «legalización de momento».

La reforma de 2011 a nuestro juicio ha pesado fuertemente en la decisión del TC. Pero el TC no repara en que la especificidad del caso, el hecho de que sea una coalición de partidos legales y que han condenado expresamente el terrorismo es, en realidad, el punctum dolens de la aplicación futura de la reforma de la LOREG. Por lo tanto, hay que tener en cuenta que este supuesto de incompatibilidad sobrevenida del art. $6.4 \mathrm{LOREG}^{35}$, y más allá de los problemas de constitucionalidad que plantea en relación al mandato representativo, supone que la Sala Especial tendría que declarar ilegales a EA y Alternatiba. Si ya ha resultado imposible entender que no pueden presentarse a unas elecciones, mucho más alejada está la idea de declararlos ilegales y disueltos por servir de sustento a ETA. No sería tampoco posible que la causa de incompatibilidad recayera única y exclusivamente sobre los candidatos independientes ya que el precepto admite en su caso sancionar sólo a los electos en candidaturas presentadas por agrupaciones de electores declaradas vinculadas a un partido ilegalizado por resolución judicial firme, pero no a los candidatos independientes.

34 «Esta panoplia de instrumentos de control a posteriori de que se ha dotado nuestro ordenamiento tras las indicadas reformas legales a fin de apreciar o no la concurrencia del supuesto previsto en el artículo 44.4 LOREG y evitar, de este modo, la posible defraudación de la Sentencia de ilegalización y disolución de un partido político, impone, desde una perspectiva constitucional y en atención a la relevancia de los derechos fundamentales en juego, en todos los supuestos que puedan activarse dichos instrumentos, pero también, sin duda, en lo que ahora importa, en el momento electoral de presentación de candidaturas y de su impugnación, una suficiente solidez y cualidad de los elementos probatorios sobre los que se sustenta la decisión judicial de anular las candidaturas presentadas por partidos políticos, federaciones o coaliciones de partidos o agrupaciones de electores que incurran en la causa prevista en el artículo 44.4 LOREG y un mayor rigor en su valoración».

35 «En todo caso serán incompatibles las personas electas en candidaturas presentadas por partidos o por federaciones o coaliciones de partidos declarados ilegales con posterioridad por sentencia judicial firme, así como los electos en candidaturas presentadas por agrupaciones de electores declaradas vinculadas a un partido ilegalizado por resolución judicial firme...». 
La reforma de 2011 lo que hace en definitiva es cubrir lagunas en materia de sucesión fraudulenta, se añade pues a los mecanismos existentes pero no los sustituye. Por tanto, no se puede admitir que no es constitucional, o quizás oportuno, el control ex ante y que hay que esperar a que se consume el riesgo para que el Estado democrático para actuar, y así ha sido admitido por el Tribunal Constitucional durante ocho años y así lo considera también el propio Tribunal Europeo de Derechos Humanos ${ }^{36}$.

\section{TITLE: The banning of political parties}

ABSTRACT: The case is somewhat Bildu a break with the doctrine that the Constitutional Court has constructed about the outlawing of political parties. The control of political parties in the process of proclamation of candidates, the value of the condemnation of terrorism and the role to be played to the High Court in monitoring the decisions of the Supreme Court, are in part a new meaning in the controversial decision the Constitutional Court.

RESUMEN: El caso Bildu representa, en cierta forma, una ruptura con la doctrina que el Tribunal Constitucional ha construido acerca de la ilegalización de partidos políticos. El control de formaciones políticas en la fase de proclamación de candidatos, el valor de la condena del terrorismo o el papel que le corresponde desempeñar al Alto Tribunal en la fiscalización de las decisiones del Tribunal Supremo, tienen en parte un nuevo sentido en la controvertida decisión del Tribunal Constitucional.

KeywOrds: Constitutional Court. Supreme Court. Terrorism. Political parties.

Palabras Clave: Tribunal Constitucional. Tribunal Supremo. Terrorismo. Partidos Políticos.

FECHA DE RECEPCIÓN: 31.06.2011 FECHA DE ACEPTACIÓN: 29.07.2011

36 Sentencia de 30 de junio de 2009, Herri Batasuna y Batasuna c. España: «no puede exigirse del Estado que espere para intervenir, a que un partido político se apropie del poder y comience a poner en práctica un proyecto político incompatible con las normas del Convenio y de la democracia, adoptando medidas concretas dirigidas a realizar tal proyecto y aunque el peligro del mismo para la democracia esté suficientemente demostrado y sea inminente. Según este Tribunal, un tal poder de intervención preventiva del Estado es igualmente conforme con las obligaciones positivas que pesan sobre las Partes contratantes en el marco del artículo 1 del Convenio para el respeto de los derechos y libertades de las personas que dependen de su jurisdicción. En el mismo sentido se pronuncia la STS de 1 de mayo de 2011 FD 14: «en el caso de Bildu, el riesgo para la democracia se consuma con la concurrencia al proceso electoral aquí concernido, y la efectiva adquisición de la condición de cargo electo y el posterior ejercicio de las funciones de los respectivos cargos en las instituciones, con independencia de que, posteriormente pudieran ponerse en marcha los instrumentos que contempla la LOREG. En efecto, el hecho de ser proclamado candidato, y más aún adquirir la condición de cargo electo, conlleva el acceso a información pública y luego la posibilidad de adoptar decisiones y tomar acuerdos que pueden conllevar una afección sobre las personas y sobre la misma sociedad...Y este dato es relevante desde la perspectiva que impone el obligado respeto al principio de proporcionalidad al que nos hemos referido en el fundamento jurídico séptimo de esta nuestra sentencia...». 
